p ISSN: 1410-9344, e ISSN: 2549-5631

\title{
PKU BAGI MI MUHAMMADIYAH MADUKORO DAN WONOGIRI KABUPATEN MAGELANG MELALUI IMPLEMENTASI STANDAR NASIONAL PENDIDIKAN DASAR DALAM PENGEMBANGAN MUTU MADRASAH
}

\author{
${ }^{1)}$ Ahwy Oktradiksa, ${ }^{2)}$ Kanthi Pamungkas Sari, ${ }^{3)}$ Norma Dewi Shalikhah \\ ${ }^{1), 2), 3) F a k u l t a s}$ Agama Islam Universitas Muhamadiyah Magelang \\ 1) email: ahwy@ummgl.ac.id \\ 2) email: kpamungkassari@ummgl.ac.id \\ 3) email: normadewi@ummgl.ac.id
}

\begin{abstract}
The issues facing the Madrasah Ibtidaiyah Muhammadiyah Madukoro and Magelang Regency Wonogiri is a low level of understanding of knowledge about SNP, inequalities in educational development, objective conditions of teachers and resources involved have the ability of low, low management capabilities of the madrasa, lack the support of stakeholders in the development of the madrasa. The purpose of the research is accomplishing the implementation system national standards of education through madrasah quality development with the learning media design is good. The methods used are participatory empowerment model i.e. Participatory Rural Appraisal (PRA). The results of the devotion to the development of quality learning through the medium of the madrassa showed good results because of the understanding of national standards of education in madrasah is in need of mentoring that is accurate in order to realize a superior madrasah and produce competent graduates through teaching with creative learning media.
\end{abstract}

Keywords: SNP, Qualiity Improvement, Madrasah Ibtidaiyah

\section{PENDAHULUAN}

\section{Analisis situasi}

Meningkatkan mutu MI adalah menjadi kebutuhan yang harus dilakukan, yaitu dengan pemberdayaan madrasah (schools empowerment). Pemberdayaan yang dimaksud di sini adalah sistem pendidikan bermutu kepada masyarakat yang ditunjang oleh tiga apek, yaitu manajemen yang rapi, tenaga pendidik (guru) profesional, serta dana dan fasilitas pendidikan yang memadai. MI yang dikelola dengan tertib dan rapi akan memiliki kesempatan besar untuk menjadi sebuah lembaga pendidikan yang berkualitas dan dibutuhkan oleh masyarakat di era globalisasi yang begitu banyak di warnai oleh faham materialistik. Jika ketiga aspek tersebut di atas dimiliki, MI akan dapat mencapai standar atau patokan yang dijadikan pagu, yaitu standar nasional pendidikan.

Namun dalam kenyataannya, pengembangan mutu madrasah di daerah dihadapkan pada masalah-masalah yang fundamental seperti: 1) rendahnya pengetahuan dan pemahaman tentang Standar Nasional Pendidikan (SNP) sehingga akan berdampak pada pelaksanaan proses pendidikan yang berkualitas; 2) terjadinya ketidaksetaraan dalam pengembangan pendidikan utama jika dibandingkan dengan sekolah umum; 3) kondisi obyektif dari guru dan sumber daya terlibat memiliki kemampuan yang terbatas dalam mendukung proses pembelajaran berkualitas; 4) rendahnya kemampuan 
manajemen madrasah; 5) minimnya dukungan stakeholders madrasah dalam pengembangan madrasah baik secara moril maupun materiil.

Kondisi tersebut diatas juga dihadapi oleh lembaga-lembaga pendidikan madrasah baik negeri maupun swasta di daerah Kabupaten Magelang. Di Kabupaten Magelang memiliki 310 Madrasah Ibtidaiyah (MI) negeri dan swasta yang tersebar di 21 kecamatan. Jika di rata-rata setiap kecamatan memiliki 14 sampai 15 MI. Menurut data yang diperoleh dari Badan Akreditasi Nasional Madrasah dan Sekolah (BANSM.or.id) tahun 2015, madrasah yang memiliki akreditasi peringkat A ada $7 \mathrm{MI}$, peringkat B sejumlah $60 \mathrm{MI}$ dan yang memiliki peringkat $\mathrm{C}$ ada $21 \mathrm{MI}$. Ini berarti masih sebagian besar MI yang belum terakreditasi jika dibandingkan dengan yang sudah terakreditasi. Bagi MI yang sudah terakreditasipun bukan berarti tidak memiliki permasalahan yang berarti. Mereka masih cukup rapuh apabila tidak diberikan penguatan kelembagaan secara sungguhsungguh dan berkelanjutan, utamanya dalam pengembangan mutu madrasah. Jika hal tersebut tidak diupayakan maka yang paling besar kena imbasnya adalah para peserta didik.

\section{Masalah mitra}

Dari analisis situasi diatas dapat kita tarik kesimpulan bahwa MI pengembangan mutu madrasah menjadi sebuah keniscayaan dan bahkan keharusan. Namun dalam pelaksanaanya muncul permasalahan yang dialami oleh mitra. Berikut disampaikan beberapa hal yang dikeluhkan oleh mitra : a) Pemahaman tentang SNP; Belum pernah ada sosialisasi yang detail dan menyeluruh tentang SNP dari pihak-pihak terkait. Mitra sebenarnya sangat membutuhkan informasi tersebut agar program kerja madrasah yang tersusun dapat lebih mengarah pada pencapaian kualitas pendidikan yang diharapkan oleh regulasi. B) Pengembangan Mutu MI; Proses realisasinya sampai saat ini terus mengalami kendala-kendala yang berarti. Selama ini menyusun program kerja tahunan masih dengan cara yang konvensional menurut tradisi yang ada. Belum berangkat dari permasalahan yang paling mendasar/ akar masalah yang sesungguhnya. Dan juga karena keterbatasan pemahaman tentang SNP masih terbatas maka program kerja tersebut belum mengarah pada SNP. Dokumen mutu yang ada masih sangat minim disusun bukan untuk kepentingan yang strategis bagi pengembangan madrasah sehingga baru hanya sekedar bersifat administratif saja.

Adanya kondisi obyektif madrasah yang demikian mendorong pihak pengelola MIM Wonogiri Sawangan bermaksud untuk mengadakan perbaikan madrasah agar benarbenar memiliki mutu standar pendidikan nasional kepada tim untuk membantu dan mendampingi. Adapun kendala yang dihadapi MI Muhammadiyah Madukoro Kajoran dan Wonogiri Kabupaten Magelang secara umum : 1) Fasilitas sarana prasarana yang belum lengkap/masih membutuhkan standarisasi, 2) Sumberdaya Manusia dari tenaga pengajar yang memiliki kompetensi terbatas, 3) Masih adanya sentimentil organisasi berbeda di beberapa kalangan masyarakat sehingga enggan memasukkan putra putrinya ke MI Muhammadiyah Madukoro, 4) Belum optimalnya peran Komite sekolah dan beberapa stakeholder lainnya, 5) Input siswa masih $100 \%$ berasal dari daerah local, 6) Belum memiliki tenaga kependidikan sesuai Standar Pelayanan Minimal Pendidikan, 7) Masih kurangnya jiwa visioner pada tenaga pengajar disebabkan kurangnya wawasan dan belum banyak mengikuti seminar maupun workshop, 8) Jumlah walimurid dengan tingkat pendidikan rendah (lulusan SD dan SMP, bahkan tidak lulus SD) kurang lebih masih $70 \%$ sehingga belum banyak mendukung proses pendidikan, 9) Keterbatasan sumber dana karena hanya mengandalkan sumber dana BOS yang sudah terserap untuk honor tenaga pendidik dan tenaga kependidikan, 10) Belum optimalnya peran Komite sekolah dan beberapa stakeholder lainnya

Selanjutnya agar kegiatan dapat berlangsung dengan baik dan menghasilkan output sebagaimana yang diharapkan 
bersama maka tim menyusun usulan Program Kemitraan Universitas (PKU) dalam program kegiatan pendampingan pengembangan mutu madrasah.

\section{Tujuan}

Ada dua tujuan yang akan dicapai dalam pelaksanaan pengabdian ini Tujuan Jangka Panjang: 1) Menyusun dokumen kebijakan peningkatan mutu pendidikan khususnya madrasah oleh Majelis Dikdasmen Kapupeten Magelang. 2) Menentukan rencana tindakan dalam upaya peningkatan mutu pendidikan bagi Sekolah (MI) di Kabupaten Magelang. Jangka Pendek meliputi : 1) Ketercapaian impleentasi SNP bagi guru MI Muhammadiyah Madukoro Kajoran dan Wonogiri Sawangan Kabupaten Magelang. 2) Ketercapaian pemahaman SNP bagi guru MI Muhammadiyah Madukoro Kajoran dan Wonogiri Sawangan Kabupaten Magelang

\section{Manfaat}

1. Potensi sosial dan ekonomi; Program pengabadian kepada masyarakat dengan tema pendampingan dan pengembangan mutu madrasah memberikan dampak positif dari sisi sosial yaitu stakeholder akan lebih mempercayakan peserta didik dibawah pengajaran dan pembelajaran oleh MI Muhammadiyah Madukoro Kajoran dan Wonogiri Sawangan dengan sistem pendampingan oleh Tim Pengembangan Mutu Madrasah sehingga menghasilkan outcomes/lulusan yang unggul. Dari sisi ekonomi akan ada peningkatan sumber pendapatan dimana para guru madrasah akan terangkat kesejahteraanya sesuai dengan usaha dan semangat dalam meningkatkan kualitas dan kuantitas mutu madrasah.

2. Nilai tambah dari sisi IPTEKS; Salah satu program pendampingan pengembnagn mutu madrasah adalah peningkatan kualitas SDM dengan Pelatihan pengembangan metode pembelajaran bagi guru dengan tujuan meningkatkan keterampilan guru dalam mengimplementasikan metode pembelajaran yang lebih aktif, kreatif dan inovatif melalui praktik pembuatan media pembelajaran. Hal ini untuk mengatasi keadaan guru kelas yang tidak memiliki latar belakang pendidikan yang linier sebagai guru kelas. Guru diharapkan dapat menguasai 3 sampai 5 metode pembelajaran yang aktif, kreatif dan inovatif.

3. Dampak manfaat; Lembaga Pendidikan Dasar seperti Madrasah Ibtidaiyah (MI) adalah awal dari sebuah proses pencapaian keberhasilan guna mengenal jati diri siswa untuk meraih mimpi menjadi manusia cerdas dan bermutu dari sisi kognitif, afektif, dan psikomotoriknya. Untuk mencapai itu semua maka perlu dilakukan kajian yang lebih mendalam tentang ketercapaian implementasi pemahaman Standar Nasional Pendidikan khususnya pendidikan dasar (MI) untuk menuju madasah unggul dan kompetetif sebagai sumber inti untuk menghasilkan lulusan yang berkualitas.

4. Nilai tambah bagi Universitas Muhamadiyah Magelang (UM Magelang); Dengan adanya program pendampingan pengembangan mutu madrasah maka adakan tercipta program jaringan madrasah LabSchool, yang merupakan salah satu program unggulan di Program Studi Pendidikan Guru Madrasah Ibtidaiyah Fakultas Agama Islam (Prodi PGMI FAI UMMagelang) yang dilaksanakan setiap semester dengan pembentukan Tim Pengembangan Mutu Madrasah.

\section{METODE PELAKSANAAN KEGIATAN}

Metode yang akan dipakai dalam kegiatan ini adalah model pemberdayaan masyarakat partisipatif yaitu Participatory Rural Apraisal (PRA). Metode tersebut dibagi menjadi tiga tahap yaitu: 1) Persiapan: Memberitahukan kegiatan yang akan dilaksanakan kepada Kepala Kantor Kementrian Agama Kabupaten Magelang melalui Kasie Pendidikan Madrasah, 
Menyampaikan ijin kepada kepada Kepala Kantor Kementrian Agama Kabupaten Magelang melalui Kasie Pendidikan Madrasah, yang wilayahnya digunakan sebagai lokasi kegiatan pengabdian pada masyarakat ini, Menyiapkan teknologi yang akan diterapkan kepada sasaran mitra, Menyusun jadwal kegiatan dan melakukan pembagian tugas di antara anggota tim sebagaimana berdasarkan kompetensi masing-masing. 2) Pelaksanaan: Sosialisasi dan Diskusi tentang SNP kepada pengelola MI yang terdiri dari Kepala Madrasah dan semua guru serta Komite Madrasah, Evaluasi atas peningkatan pemahaman peserta tentang SNP, Sosialisasi tentang dokumen mutu MI kepada pengelola Madrasah, Pendampingan penyusunan dokumen mutu MI diantaranya : evaluasi diri /pemetaan masalah madrasah dengan menggunakan analisis SWOT yang melibatkan seluruh pengelola dan Komite Madrasah beserta Kasie Madrasah Kemenag Kabupaten Magelang; Rencana Program Kerja Madrasah; Dokumen-Dokumen Mutu yang belum dimiliki madrasah, jenis atau nama dokumen yang akan disusun setelah mendapatkan informasi dari pemetaan masalah dan rencana program kerja, Pelatihan pengembangan metode pembelajaran aktif, kreatif, dan inovatif bagi guru. Hal ini bertujuan untuk merespon masalah guru yang tidak memiliki latarbelakang pendidikan yang linier sebagai guru kelas, dan juga meningkatkan kualitas pembelajaran yang diharapkan akan berimbas pada peningkatan kualitas lulusan, Pelatihan penggunaan berbagai macam dan karakteristik media pembelajaran bagi guru. Tujuan kegiatan ini adalah untuk meningkatkan motivasi belajar peserta didik. Karena proses pembelajaran yang saat ini didominasi menggunakan cara yang konvensional dan menggunakan media pembelajaran yang sangat terbatas, Evaluasi peningkatan keterampilan guru dalam menggunakan metode dan media pembelajaran, Memetakan kemungkinan peluang kerjasama dengan pihak luar yangdapat dibangun dan ditindaklanjuti guna pengembangan mutu madrasah yang lebih baik, Menyusun beberapa naskah kerjasama dengan pihak-pihak terkait dan menindaklanjuti sesuai dengan kesepakatan waktu yang ditentukan, 3) Penyusunan laporan : Penyusunan laporan kemajuan, sudah selesai dalam waktu sesuai dengan jadwal yang telah ditentukan, Penyusunan laporan akhir beserta seluruh instrument pelaporan seluruh kegiatan pengabdian pada masyarakat ini sudah selesai.

\section{HASIL PELAKSANAAN KEGIATAN}

Kegiatan awal yang dilakukan adalah, melakukan koordinasi dengan pihak MI Muhammadiyah Madukoro dan Wonogiri kabupaten Magelang, dengan membawa surat tugas program kemitraan universitas melalui program pengabdian guna melakukan persamaan persepsi tentang pengembangan mutu madrasah melalui SNP berupa pendampingan desain media pembelajaran berbasis kearifan lokal. Pada pelaksanaannya sesuai metode yang kami gunakan dalam program kemitraan ini adalah Participatory Rural Apraisal (PRA), maka semua elemen pengelolah MI Muhammadiyah (Kepala Sekolah dan Guru) sudah terlibat, ini sesuai dengan komitmen warga madrasah untuk mewujudkan madrasah yang berkualitas.

\section{Standar Nasional Pendidikan MI Muhamadiyah Madukoro dan Wonogiri Kabupaten Magelang}

Proses pelakanaan dalam pemahaman SNP adalah di MI Muhammamdiyah Madukoro dan Wonogiri yaitu mengkonfirmasi pemahaman semua guru dan khususnya kepala madrasah sebagai pemangku kebijakan untuk menyamakan persepsi tentang makna pengembangan mutu melalui akreditasi masing-masing Madrasah yang sudah diraih, yang pada akhirnya berdampak pada penyamaan persepsi dalam menjalankan madrasah sebagai wadah pengembangan pendidikan. Kegiatan ini dilakukan pada hari kamis, tanggal 31 Agustus 2017 yang menghasilkan : 1) Madrasah Ibidaiyah berdasarkan sumber BPS Kabupaten dan BANS.or.id bahwa masih sekita 229 Sekolah Dasar dan Madrasah 
Ibtidaiyah belum terakreditasi, 2) SDM yang meliputi guru, staff, komite MI yang kurang profesionalisme dalam mengelola lembaga pendidikan, kurang responsive terhadap dinamika perubahan kebijakan pendidikan, PBM yang berjalan kurang sesuai dengan prinsip pembelajaran karena sebagian besar tenaga pendidik bukan berlatar belakang pendidikan keguruan, 3) profil siswa berupa masukan peserta didik yang kurang selektif menyangkut usia dan kematangan siswa sehingga pihak MI mau menerima siswa yang usianya belum mencukupi untuk pendidikan tingkat dasar dengan alasan takut tidak mendapatkan siswa, 4) Sarana dan prasarana MI yang ala kadarnya sehingga berdampak pada lulusan yang kurang memenuhi harapan dan kebutuhan masyarakat yang memnginginkan nilai lebih seperti slogan MI sebagai penyelenggara pendidikan dasar plus agama.

Sejak keluarnya Peraturan Pemerintah Nomor 19 tahun 2005 maupun tahun 2009 tentang SNP sampai saat ini pihak pengelola madrasah belum pernah mendapatkan informasi yang detail dan menyeluruh tentang SNP. Hal ini terjadi karena belum pernah ada sosialisasi yang detail dan menyeluruh tentang SNP dari pihak-pihak terkait. Mitra sebenarnya sangat membutuhkan informasi tersebut agar program kerja madrasah yang tersusun dapat lebih mengarah pada pencapaian kualitas pendidikan yang diharapkan oleh regulasi.

Pengembangan mutu pendidikan sudah diupayakan oleh mitra, dengan melalui program kerja tahunan yang disusun oleh pengelola madrasah bersama komite. Namun dalam perjalanan proses realisasinya sampai saat ini terus mengalami kendalakendala yang berarti. Selama ini menyusun program kerja tahunan masih dengan cara yang konvensional menurut tradisi yang ada. Belum berangkat dari permasalahan yang paling mendasar/akar masalah yang sesungguhnya. Dan juga karena keterbatasan pemahaman tentang SNP masih terbatas maka program kerja tersebut belum mengarah pada SNP. Dokumen mutu yang ada masih sangat minim disusun bukan untuk kepentingan yang strategis bagi pengembangan madrasah sehingga baru hanya sekedar bersifat administratif saja.
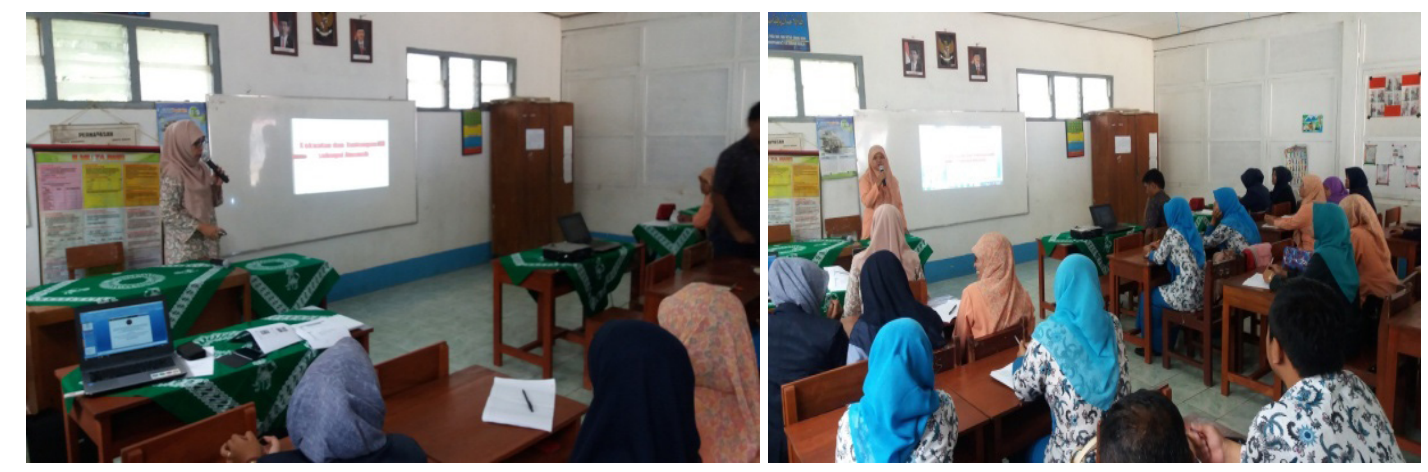

Gambar 1. Sosialisasi SNP Bagi Guru MI

Adapun usaha untuk mengatasi persoalan yang terjadi maka program penjelasan pemahaman SNP menjadi sangat bermanfaat bagi MI Muhammadiyah Madukoro dan Wonogiri yaitu dengan memperhatikan UU No 20 tahun 2013 pasal 1, ayat 17 dikemukakan bahwa SNP adalah kriteria minimal tentang standar pendidikan di seluruh wilayah hukum NKRI, dan pasal 1, ayat 3 dijelaskan Sistem Pendidikan
Nasional adalah kesluruhan komponen pendidikan yang saling terkait secara terpadu untuk mencapai tujuan pendidikan nasional. Petunjuk teknisnya adalah Peraturan Pemerintah No 19. Tahun 2005 tentang Standar Pendidikan Nasional, pada Bab II pasa 2, dijelaskan lingkup Stadar Pendidikan Nasional Meliputi : 1) standar isi, 2) standar proses, 3) standar komptensi lulusan, 4) standar pendidikan dan tenaga kependidikan, 
5) standar sarana dan prasarana, 6) standar pengelolahan, 7) standar pembiyaan, 8) standar penilaian pendidikan. Untuk mempertegas proses pengembangan mutu marasah di MI Muhammadiyah Madukoro dan Wonogiri Kabupaten Magelang dalam usaha mengorganisasikan lembaga pendidikan maka diperlukan sosialisasi SNP agar tercipta rasa tanggung jawab dan profesionalisme kerja antara kepala madrasah, guru, dan tenaga kependidikan yang meliputi : 1) guru harus memiliki kualifikasi akademik minimum, 2) guru agama, penjaskes, dan kesenian mengajar sesuai dengan latar belakang pendidikannnya, 3) kepala madrasah berstatus sebagai guru, memiliki sertifikat pendidik, dan SK sebagai Kepala madrasah, 4) kepala madrasah memiliki kualifikasi akademik minimum srjana (S1) atau Diploma emapat (D-IV), 5) Kepala madrasah memiliki kemampuan manjerial yang ditunjukan dengan kemajuan dalam mengelola kesiswaan, guru, tendik, pengembangan kurikulum, sarpras, pembiyaan, dan humas, 6) kepala madrasah memiliki kemampuan kewirausahaan yang ditunjukan dengan adanya kegiatan kewirausahaan sebagai sumber belajar siswa koperasi siswa, perternakan/ perikanan,pertanian/perkebunan, kantin sekolah, unit produksi, 7) kepala madrasah memiliki kemampuan kerjasama dengan pihak lain untuk kepentingan madrasah, berpartisifasi dalam kegiatan sosial kemasyarakatan, memiliki kepekaan sosial terhadap orang atau kelompok lain, 8) tenaga kependidikan minimum memiliki kualifikasi akademik pendidikan menengah atau yang sederajat, 9) tenaga perpustakaan minimum memiliki kualifikasi akademik pendidikan menengah atau perpustakaan, 10) madrasah memiliki petugas layanan khusus pejaga sekolah, tukang kebun, tenaga kebersihan, pengemudi, pesuruh [1]. Dari beberapa landasan tersebut yang harus diperhatikan dalam pelaksanaan SNP di MI Muhammadiyah Madukoro dan Wonogiri kabupaten magelang diperlukan startegi sebagai berikut : 1) niat, 2) membangun team work yang solid, 3) mapping kekuatan, kelemahan, peluang dan tantangan, 4) menyusun perencanaan, 5) pelaksanaan kegiatan, 6) Evaluasi dan rencana tindak lanjut program kerja [2].

\section{Pengembangan Mutu Madrasah Melalui Desain Media Pembelajaran di MI Muhamadiyah Madukoro dan Wonogiri}

Pengembangan media pembelajaran yang dilakukan dalam proses pengajaran di MI Muhammadiyah Madukoro dan Wonogiri kabupaten Magelang belum berjalan dengan baik seiring dengan masih banyaknya guru menganggap pembelajaran hanya cukup dengan Buku Pegangan Guru, Buku Cetak Pegangan Siswa, Lembar Kerja Siswa (LKS) sehingga berdampak pada lulusan yang kurang kreatif dalam mendapatkan wawasan pengetahuan secara luas. Dari hasil program kemitraan melalui pengabdian maka guru harus menghasilkan program tindak lanjut berupa mendesain media pembelajaran yang dihubungkan dengan kompetensi lulusan siswa yang mampu menjelaskan materi mata pelajaran (PKn, Bahasan Indonesia, Matematika, IPS dan IPA serta Pendidikan Agama Islam) dengan baik. Dalam penjelasan media adalah apa saja yang dapat digunakan untuk menyampaikan pesan dari pengirim pesan ke penerima pesan dalam konteks komunikasi. Media pembelajaran adalah media yang digunakan dalam konteks kuminikasi dalam kegiatan pembelajaran [3]. Tujuan media adalah 1) memvisualkan yang abstrak menjadi konkrit, memperjelas penyajian pesan agar tidak terlalu bersifat verbalistik (dalam bentuk kata-kata tertulis atau lisan belaka), 3) mengatasi keterbatasan ruang, waktu, dan daya indera, 4) mempersamakan pengamatan, pengalaman dan persepsi [4]. Pertimbangan dalam pemilihan media adalah 1) tujuan pembelajaran yang akan dicapai, 2) kesesuaian media dengan materi, 3) tersedianya sarana dan prasarana, 4) memperhatikan karakteristik siswa [5]. Kriteria pemilihan media adalah 1) cost (biaya) 2) accesibility (Keterjangkauan) 3) Social-Politycal Suitable (Kesesuaian 
Sosial Politik) 4) culture frendlinenss (Ramah Budaya) 5) openess (Keterbukaan) 6) interaktivity (Interaktif) 7) motivasional (Memotivasi) 8) effectiveness (efektif) [6]. Syarat pengembangan media adalah 1) visible (mudah dilihat), 2) interesting (menarik), 3) simple (sederhana), 4) usefull (isinya bermanfaat, 5) accurate (bisa dipertanggungjawabkan, 6) legitimate (masuk akal), 7) structured (tersusun baik) [7].

Berikut media pembelajaran penunjang kegiatan pembelajaran di MI Muhammadiyah Madukoro dan Wonogiri Kabupaten Magelang:
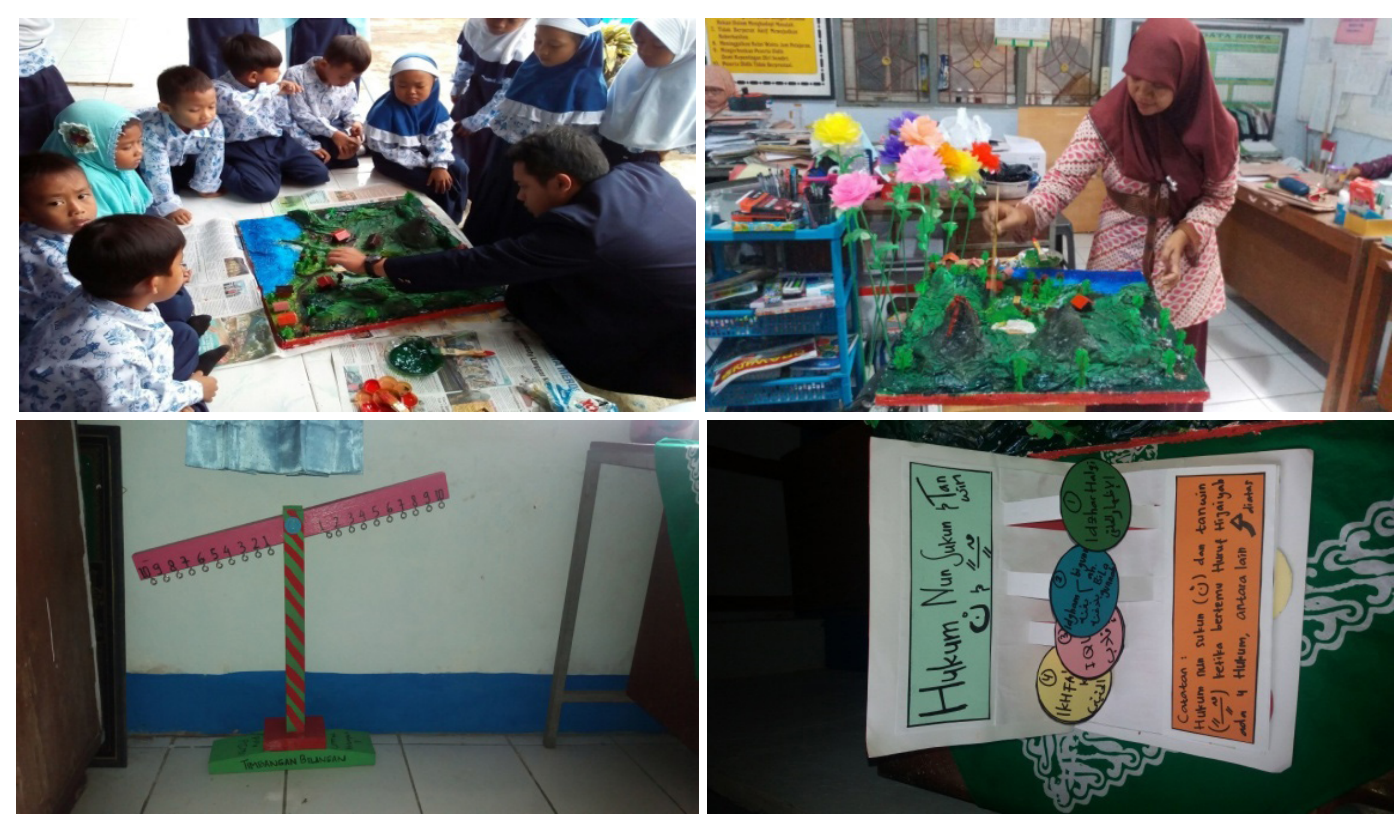

Gambar 2. Media Pembelajaran hasil kerja Guru

\section{SIMPULAN DAN SARAN}

\section{Simpulan}

Dari program kemitraan melalui pengabdian di MI Muhammadiyah Madukoro dan Wonogiri Kabupaten Magelang dapat diberikan kesimpulan bahwa pemahaman SNP masih terlalu rendah sehingga diperlukan pendamping berkelanjutan untuk mewujudkan pengembanagn mutu madrasah yang berkualitas serta melakukan pembuatan media pembelajaran sebagai penunjang strategi berbasis kearifan lokal.

\section{Saran}

Ada beberapa saran dan masukan agar pembelajaran di madrasah menjadi lebih kreatif dan bermakna, yaitu: 1) Guru harus menyadari bahwa guru selalau dalam pengawasan kebijakan kualifikasi SNP, 2) Guru harus berani mencoba dan berinovasi khususnya dengan membuat media pembelajaran sederhana unutk mengubah midset siswa MI Muhammadiyah Madukoro dan MI Muhammadiyah Wonogiri lebih baik.

\section{PERSANTUNAN}

Pada kesempatan ini, tim pengabdian kepada masyarakat menyampaikan terima kasih kepada:

1. Ir. Eko Muh Widodo, MT (Rektor Universitas Muhammadiyah Magelang), yang telah memberi kesempatan kepada tim Pengabdian Kemitraan Universitas (PKU) dalam program untuk memperoleh dana pengabdian ini.

2. Dr. Heni Setyowati, E.R, S.Kp.,M. Kes. (Ketua LP3M Universitas Muhammadiyah Magelang), yang telah meberikan fasilitas dan rekomendasi persetujuan proposal pengabdian masyarakat ini untuk mendapatkan dana dari Universitas Muhammadiyah Magelang. 
3. Dr. Nurodin Usman, LC.,MA) Dekan Fakultas Agama Islam Universitas Muhammadiyah Magelang yang telah memberi Surat Tugas kepada tim untuk melaksanakan pengabdian masyarakat ini.

4. Ibu Siti Uswatun Kahsanah (Kepala MI
Muhammadiyah Madukoro) dan M. Yuli Efendi (Kepala MI Muhammadiyah Wonogiri) yang telah memfasilitasi kegiatan sosialisasi SNP dan Praktek Media Pembelajaran sebagai Mitra kerja Prodi Pendidikan Guru MI Universitas Muhammadiyah Magelang.

\section{REFERENSI}

Peraturan Pemerintah Nomor 19 tahun 2005 tentang Standar Nasional Pendidikan

Majelis Pustaka Informasi dan Litbang, Profil Muhammadiyah Kabupaten Magelang (Peta Dakwah Muhammadiyah Berbasis Kecamatan), Daftar Amal Usaha Muhammadiyah Madrasah Ibtidaiyah Muhammadiyah Kabupaten Magelang, 2015.

Sardiman, Arif S., et al. 2006. Media Pendidikan: Pengertian, Pengembangan dan Pemanfaatannya. Jakarta: PT Raja Grafindo Persada.

Santyasa, I Wayan. 2007. Landasan Konseptual Media Pembelajaran. Singaraja: Universitas Pendidikan Ganesha, Bali.

Latuheru. 1988. Media Pembelajaran. Jakarta: Raja Grafindo Persada.

Munadi, Yudhi. 2010. Media Pembelajaran: Sebuah Pendekatan Baru. Jakarta: Gaung Persada Press.

Gerlach, V.S. \&Ely, D.P. 1980. Teaching and Media: A Systematic Approach. Englewood Cliffs, N.J.: Prentice-Hall 